\title{
The Impact of Self-Care Education with Teach-Back Method on Self- Esteem in Kidney Transplant Recipients: A Clinical Trial
}

\author{
Masoumeh Hemmati Maslak Pak ${ }^{1}$, Farzin Mollazadeh ${ }^{2 *}$, Hamidreza Khalkhali ${ }^{3}$, Saeed Abkhiz ${ }^{4}$ \\ 1. Associate Professor, Department of Nursing, Urmia School of Nursing and Midwifery, Urmia University of Medical \\ Sciences, Urmia, Iran \\ 2. MSc in Medical-Surgical Nursing, Department of Nursing, Urmia School of Nursing and Midwifery, Urmia \\ University of Medical Sciences, Urmia, Iran \\ 3. Associate Professor, Department of Epidemiology and Biostatistics, School of Public Health, Urmia University of \\ Medical Sciences, Urmia, Iran \\ 4. Assistant Professor, Department of Adult Nephrology, Urmia University of Medical Sciences, Urmia, Iran
}

\section{Article Info}

Received: 2020/02/05;

Accepted: 2020/03/25;

Published Online: 2020/08/22

10.30699/ajnmc.28.3.154

Original Article

Use your device to scan and read the article online

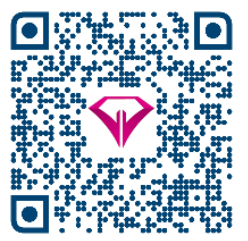

\section{ABSTRACT}

Introduction: Kidney transplantation leads to return to a healthy life and relief from hemodialysis restrictions. The benefits of kidney transplantation have been proven but require constant self-care monitoring throughout one's life and training and support. One of the new methods of training is the teach-back method used to obtain and understand information. This study aimed to determine the impact of selfcare education with Teach-Back method on self-esteem in Kidney Transplant Recipients.

Methods: In this clinical trial study, 79 renal transplant patients were selected from the clinic of Imam Khomeini Hospital in Urmia in 2016 and were randomly assigned to intervention and control groups. Then, in the intervention group, educational content about self-care with teach-back method was presented during five 60-minute sessions. Data were collected using demographic questionnaire and Rosenberg self-esteem questionnaire.

Results: Before intervention, the mean score of self-esteem was not significantly different between the control and intervention groups $(P=0.559)$. After the intervention, the intervention group had a significant increase in the mean score of self-esteem compared to the control group $(P=0.001)$.

Conclusion: In this study, self-care education with teach-back method was effective in improving the self-esteem of kidney transplant patients. And it is suggested to use the teach-back method in education of patients with kidney transplantation.

Keywords: Education, Teach-Back Communication, Kidney Transplantation, Self-esteem, Nursing

\section{How to Cite This Article:}

Hemmati Maslak Pak M, Mollazadeh F, Khalkhali H, Abkhiz S. The Impact of Self-Care Education with Teach-Back Method on Self-Esteem in Kidney Transplant Recipients: A Clinical Trial. Avicenna J Nurs Midwifery care. 2020; 28(3): 154-164 
بررسى تأثير آموزش خودمراقبتى به روش بازگشتتى بر عزتنفس بيماران با يِيوند كليه: يك كار آزمايى بالينى

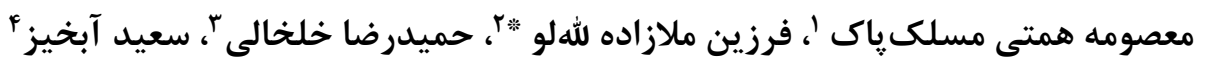

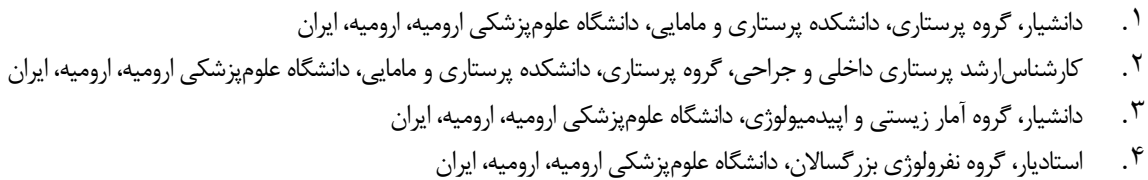

\begin{tabular}{|c|c|}
\hline جكيده & اطلاعات مقاله \\
\hline 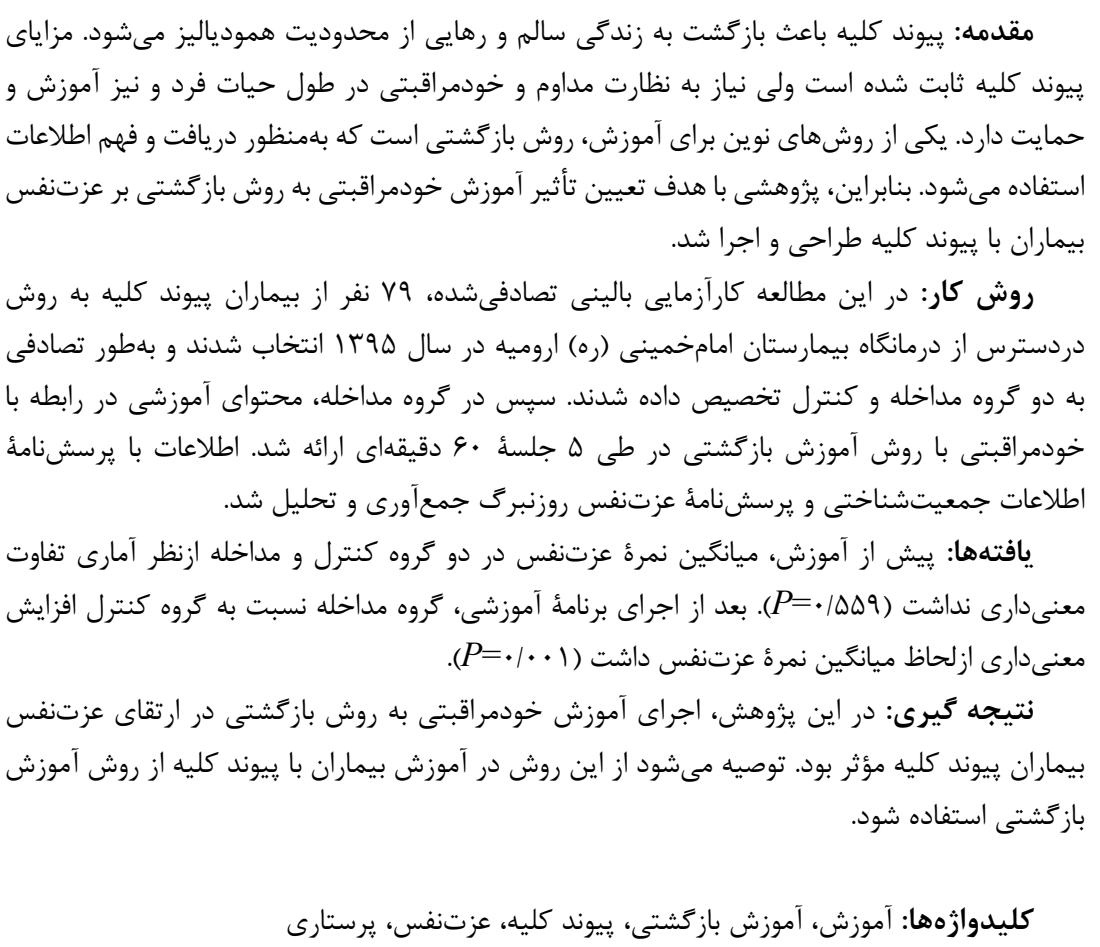 & 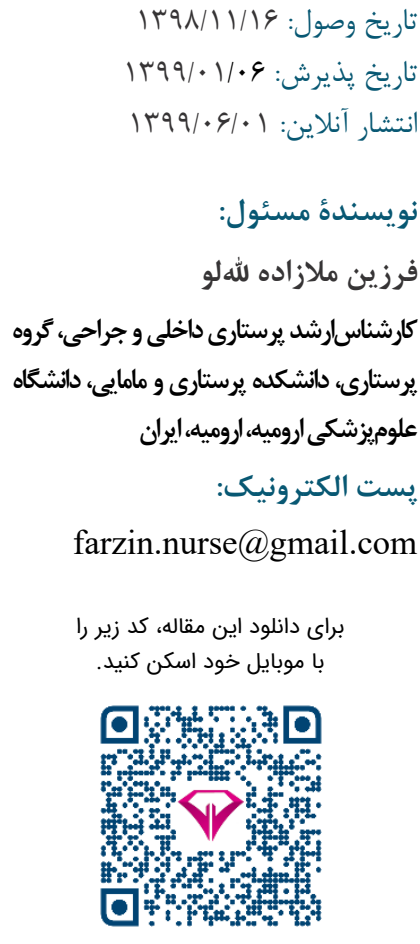 \\
\hline
\end{tabular}

آمريكا وجود دارد كه با افزودن ييوندهاى كلية سراسر جهان

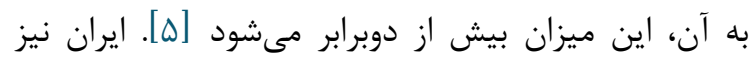

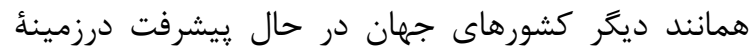

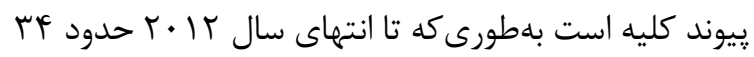

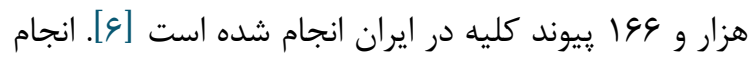
ييوند كليه موجب بازگشت به زندگى سالم و تغيير در سبك إنى

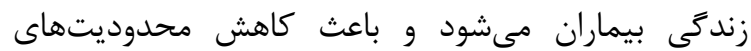
تغذيهاى و مايعات مىشود. بنابراين، پييوند فر آيندى خوشايند

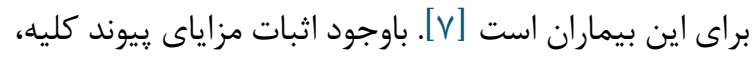

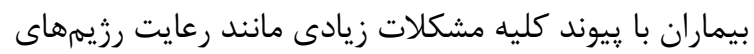

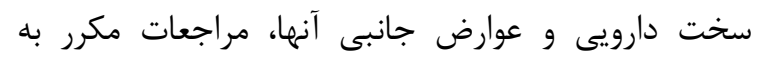

بيمارى مزمن كليه تحت عنوان كاهش غيرقابل بازگشت

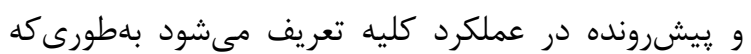
كليهها ديخر توانايى حفظ تعادل محيط داخلى بدن و حفظ

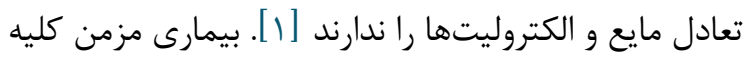
يا بهتدريج و طى ساليان متوالى يا بهدليل عدم بهببودى بيمار

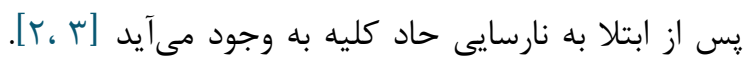

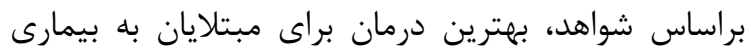

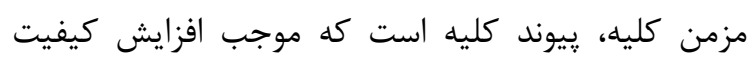

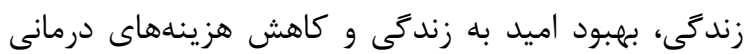
بيماران و دولت نسبت به بيماران تحتدرمان بان دياليز

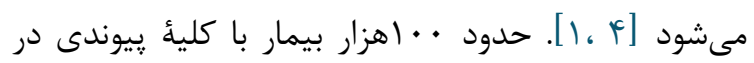


نيازمند برنامههاى آموزشى مدون هستند زيرا هدف نهايى

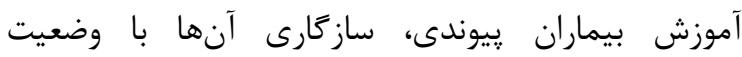
بلوجودآمده است و صرفاً انتقال اطلاعات به به آنها آموزي آناري

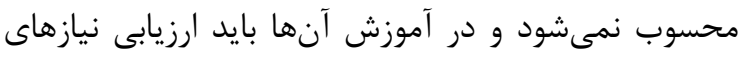

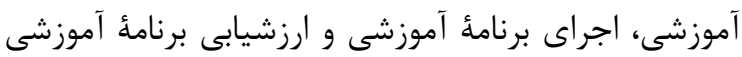

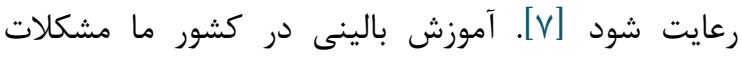
عديدهاى ازجمله استفاده از روشهاى آموزشى سنتى دالينى دارد.

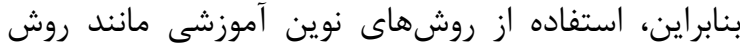

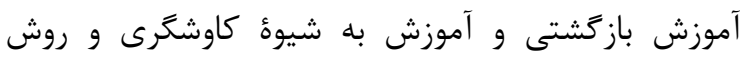

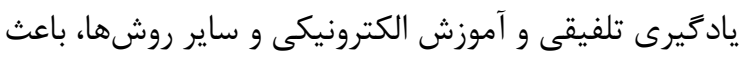
افزايش رضايتمندى و تكامل علمى بيمار ان دررابطهبا بيمارى

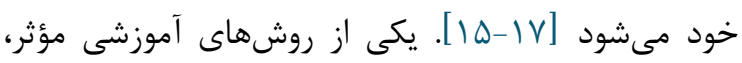

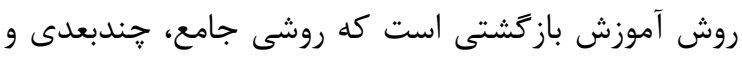

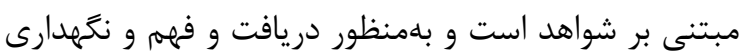

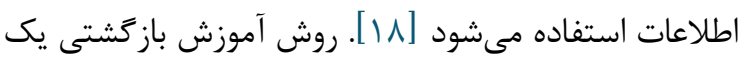

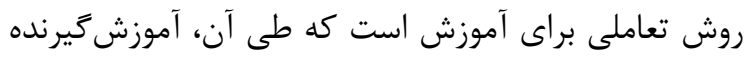

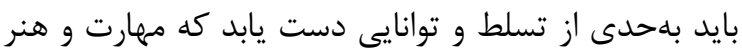

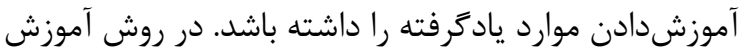

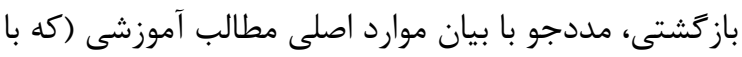

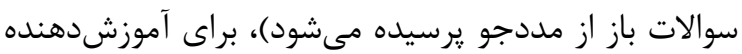

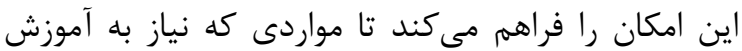
تكميلى دارد را شناسايى كند و تا زمانى كه مطالب به آنوبى إنى

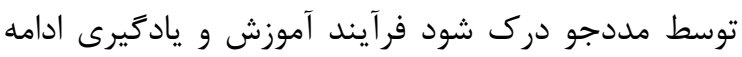

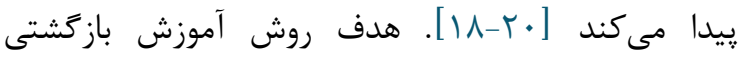
فراهمنمودن آموزشى است كه مطابق با سطح سواد

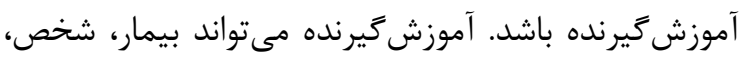

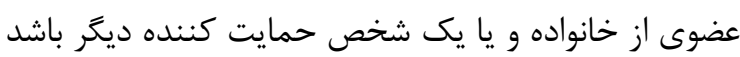

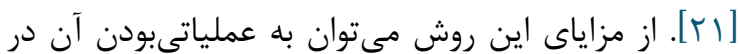

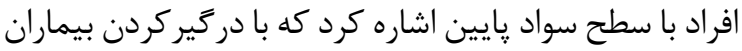

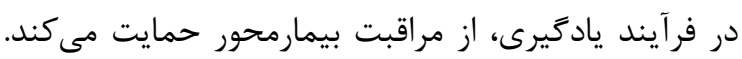

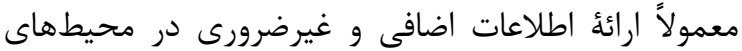
بالينى به مددجويان متداول است درحالى كه آموزش بايد

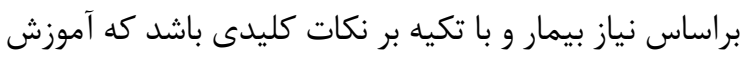

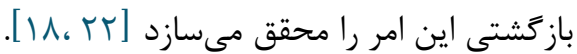
اهميت توجه به جحكونكَى آموزش بيماران ييوند كليه، امرى اساسى در درمان و مراقبت آنها است جون سهرم عمده

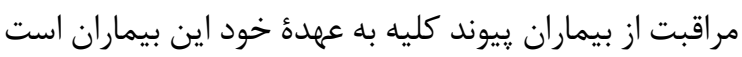

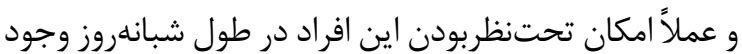

يزشك، افزايش خطر عفونت، اضطراب ناشى از رد يِيوند و

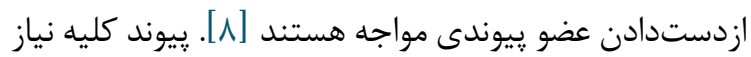

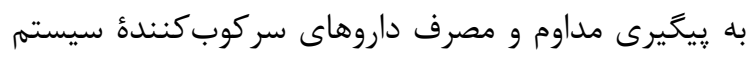
ايمنى در طول حيات فرد دارد و خودمراقبتى در اين بيماران

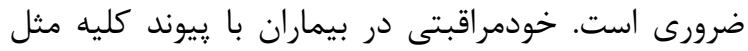

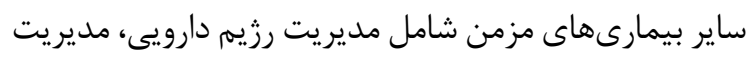

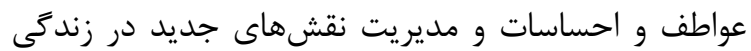

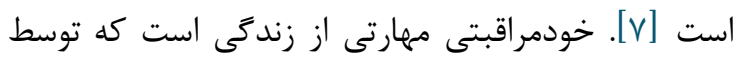
افراد براى تأمين، حفظ و ارتقاى سطح سلامتشان انجام

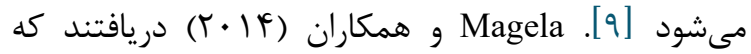
بيماران براى حفظ و بهبود عزتنفس خود نياز به آموزش

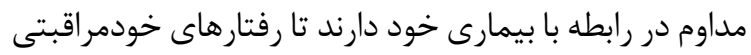

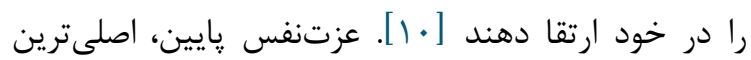

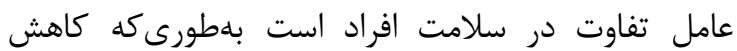

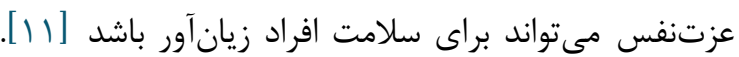

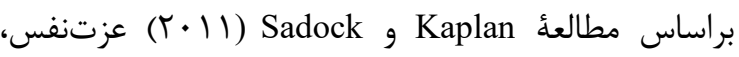
اعتماد به توانايى خود در تفكر و مقابله با خالشها، اعتها به خود براى موفقيت و زندگى شاد، احساس ارزش، داشتن حق ابراز نيازها و خواستهها، و برخوردارشدن از نتئئ

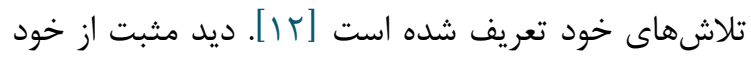
يك نيروى قوى درونى ايجاد مى كند كه باعث مىشود فرد

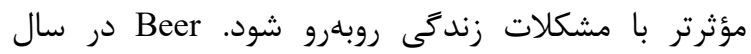

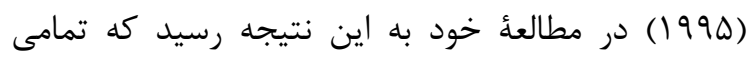
بيماران، اعم از ييوندشده، دياليز صفاقى و همودياليز، درمورد تصوير ذهنى از جسمى كه به دنبال معالجات يديد مى آيد،

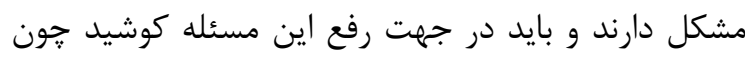

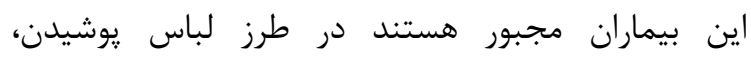
برخوردهاى اجتماعى و مسائل جنسى خود تغييراتى دهند

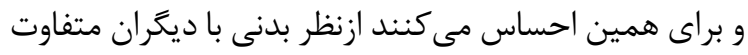

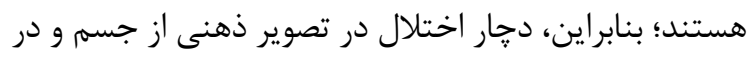
نهايت تنفر از خود مىشوند و از زندكى لذت نمى ديرند. ييوند

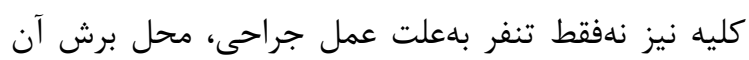
لمس كليهاى كه دقيقاً در زير يوست واقع شده است بله بلكه بله بهخاطر مصرف داروهاى ضعيفكنندة سيسته ايمنى كه

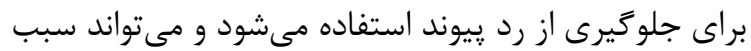

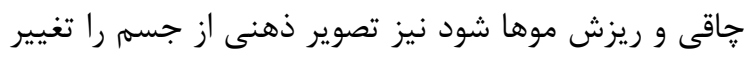

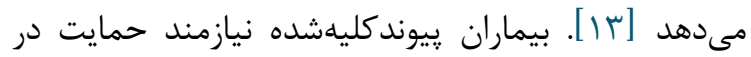

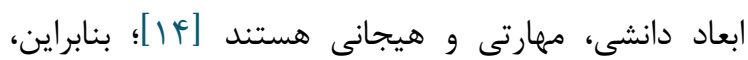




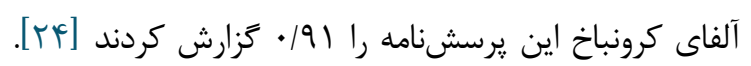

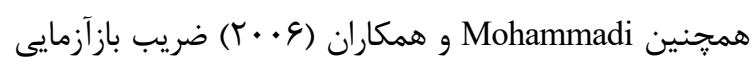

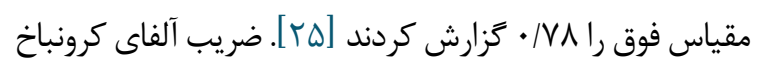

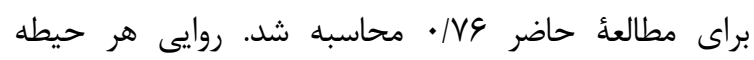

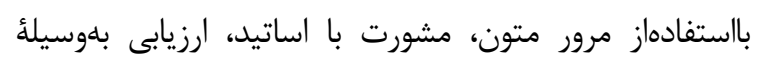

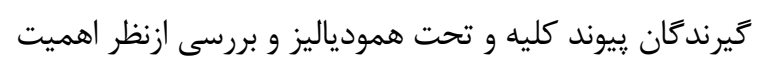

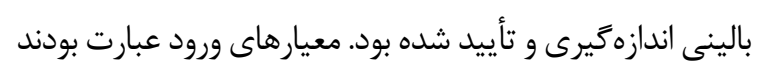

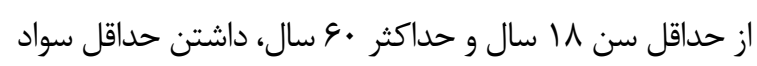

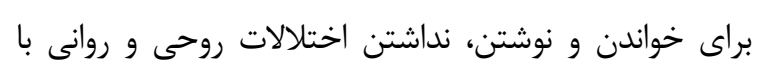

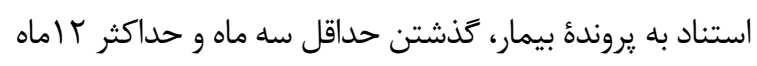

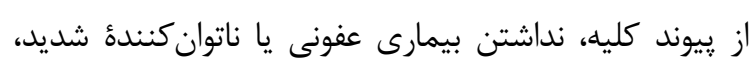

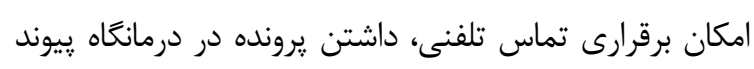

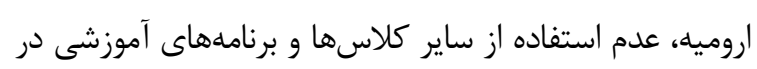

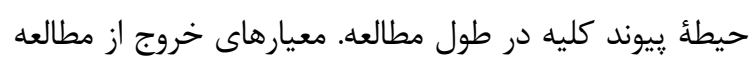

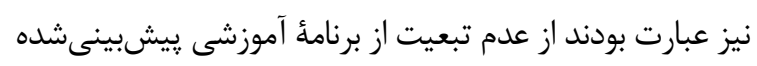

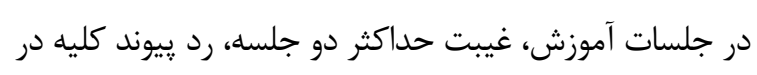

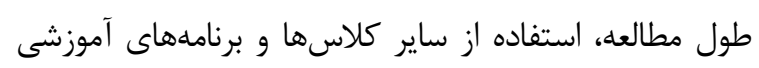

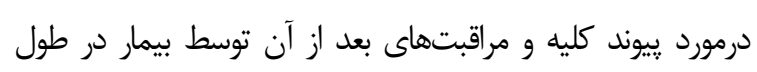

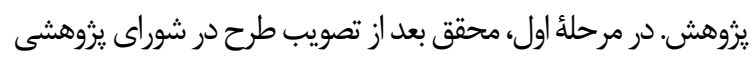

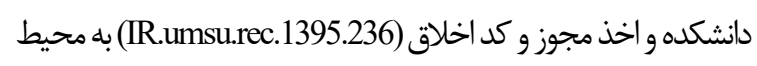
يُزوهشى كه درمانكاه بيوند مركز آموزشى و درمانى امامخمينى (رها

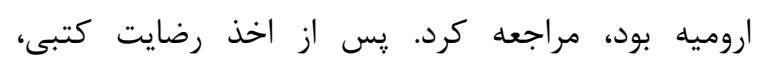

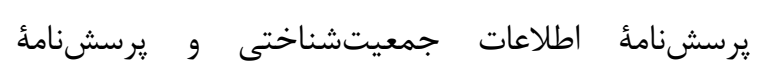

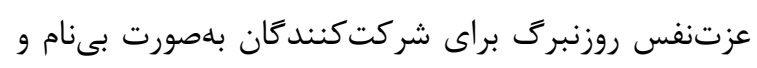

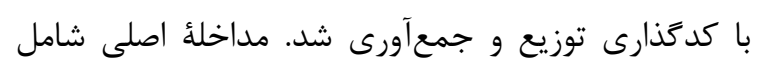

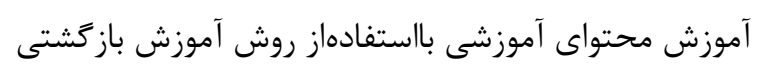

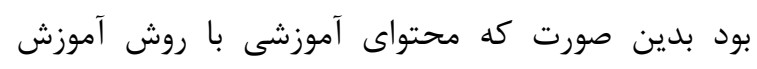

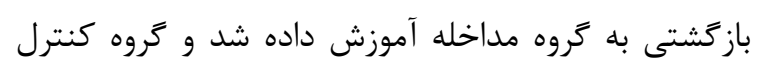

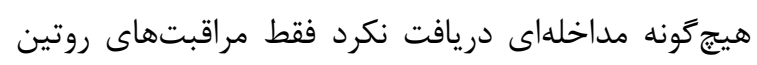

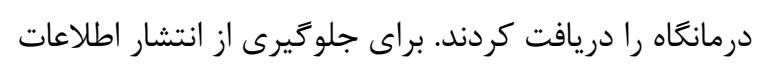

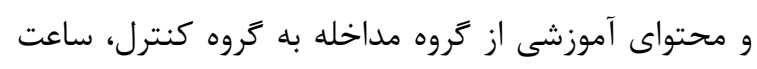

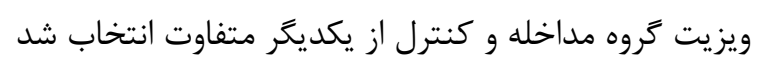

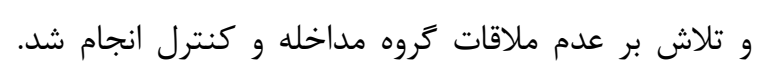

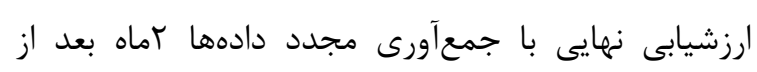

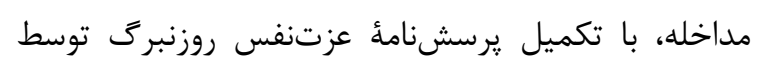

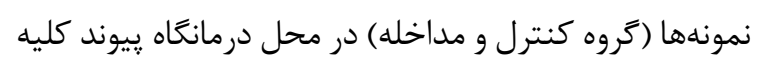

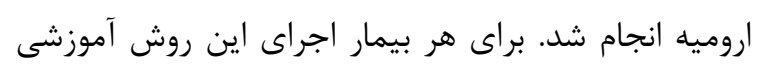

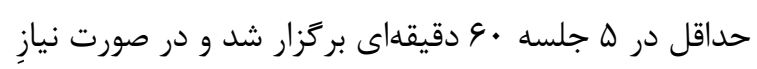

ندارد، برنامهٔ مراقبتى مددجويان يِوند كليه بهمراتب يِيجيده

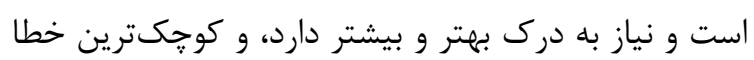

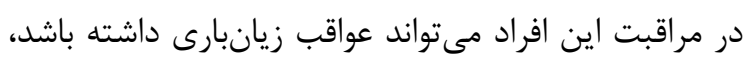

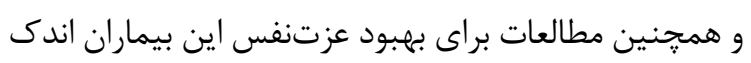
بوده و بيشتر به بررسى كميت رفتارهاى خودمراقبتى آنان

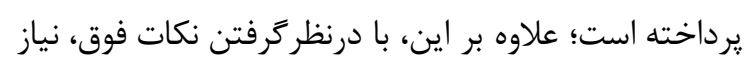

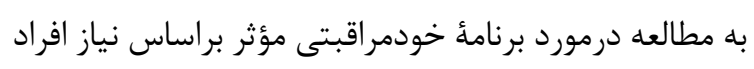

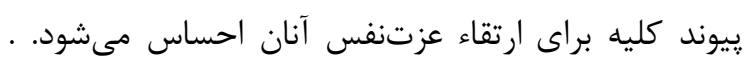

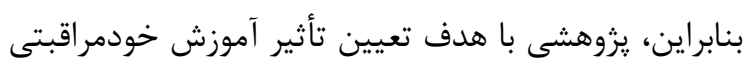

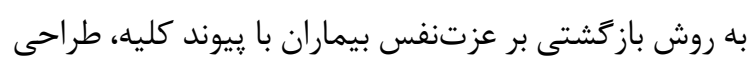

$$
\text { و اجرا شد. }
$$

\section{روشبررسى}

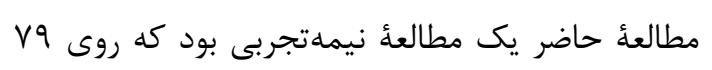

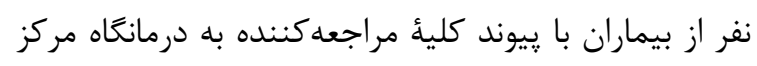

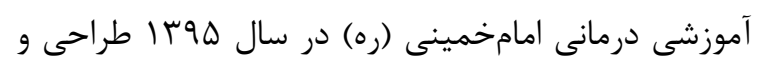

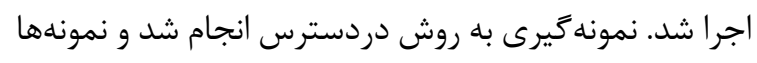

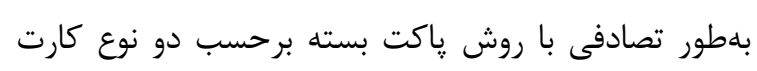

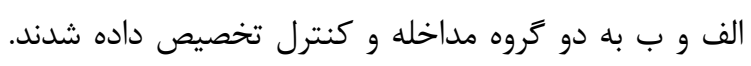

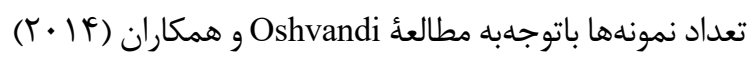

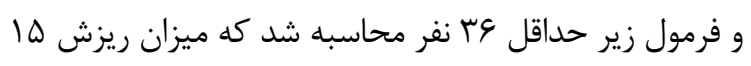

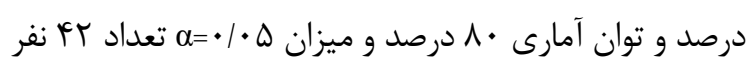

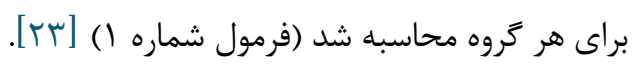
فرمول شماره اي :

$n=\frac{\left(Z \alpha / 2+Z_{-} \beta\right)^{2} \times\left(S_{1}^{2}+S_{2}^{2}\right)}{\left(x_{1}^{-}-x_{2}^{-}\right)^{2}}$ $n=\frac{(1.96+0.84)^{2} \times\left(3.2^{2}+2.6^{2}\right)}{(9.1-7.2)^{2}}=36$

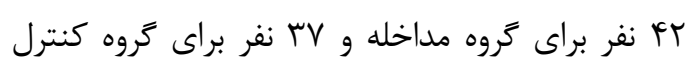

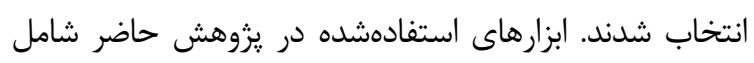

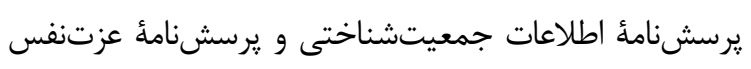

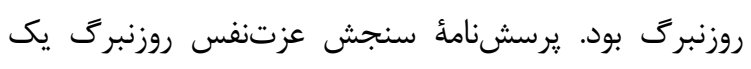

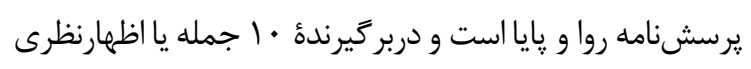

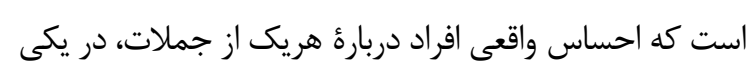

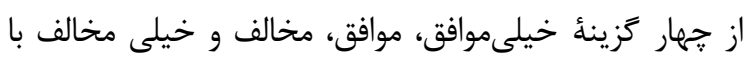

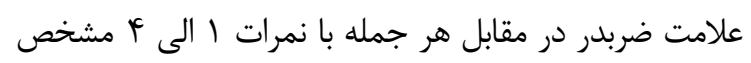

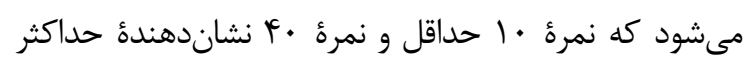

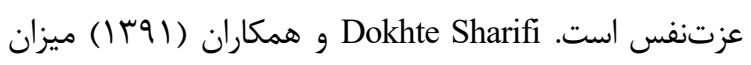


كولموكروف-اسميرنف براى بررسى نرمالبودن دادهها و از

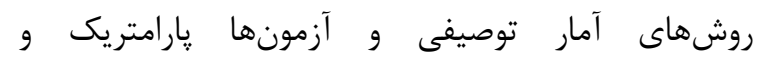

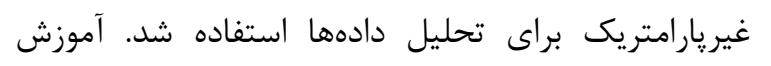

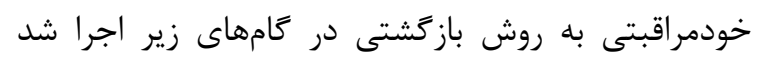

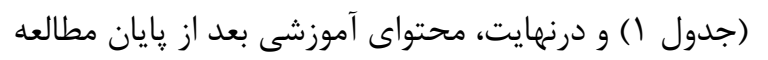
در اختيار تروه كنترل نيز قرار كرفت دمتوائ.
بيماران، تعداد جلسات افزايش يافت. دادههاى حاصل از

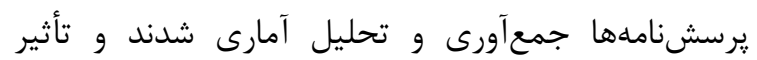

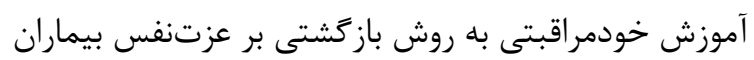

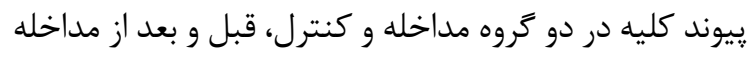
مقايسه شد. تحليل دادهاى آمارى با نرمافزار SPSS نسخه .

\section{جدول ا. جلسات آموزش خودمراقبتى به روش بازَشتى و محتواى آنها}

\begin{tabular}{|c|c|}
\hline محتواى جلسات & 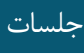 \\
\hline بررسى نيازهاى بيمار در ه حيطه خودمراقبتى باستفادهاز جكليست و تعيين كميت و كيفيت حيطههاى موردنياز & اول \\
\hline آموزش بيمار حول حيطهُ نظارت بر خود به روش آموزش بازَشتى & 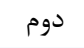 \\
\hline آموزش بيمار حول حيطهُ رفتار خودمراقبتى در زندگى روزانه به روش آموزش باز گشتى & 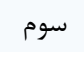 \\
\hline 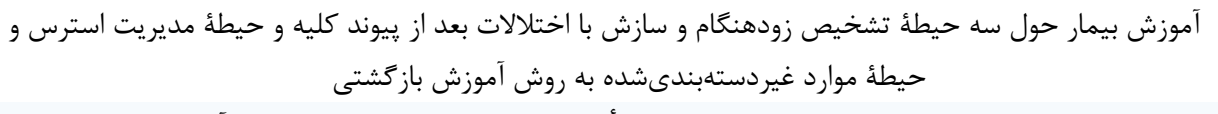 & 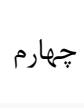 \\
\hline بيان مطالب كَفتهشه در جلسات اخير توسط مددجو با تأكيد بيشتر روى مطالبى كه بيمار در آنها ضعف داشته و در & ينجم \\
\hline
\end{tabular}

جنس، تاهل، تحصيلات، شغل، محل سكونت، نوع دهندة كليه،

بافته ها

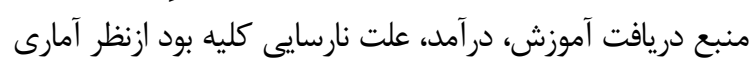

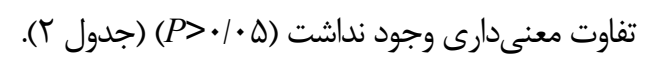

آزمون كاىدو و تست linear by linear نشان داد كه بين كروه كنترل و مداخله ازنظر مشخصات جمعيتشناختى كيفى كه شامل

جدول r. مقايسه مشخصات جمعيتشناختى كيفى بين دو تروه كنترل و مداخله

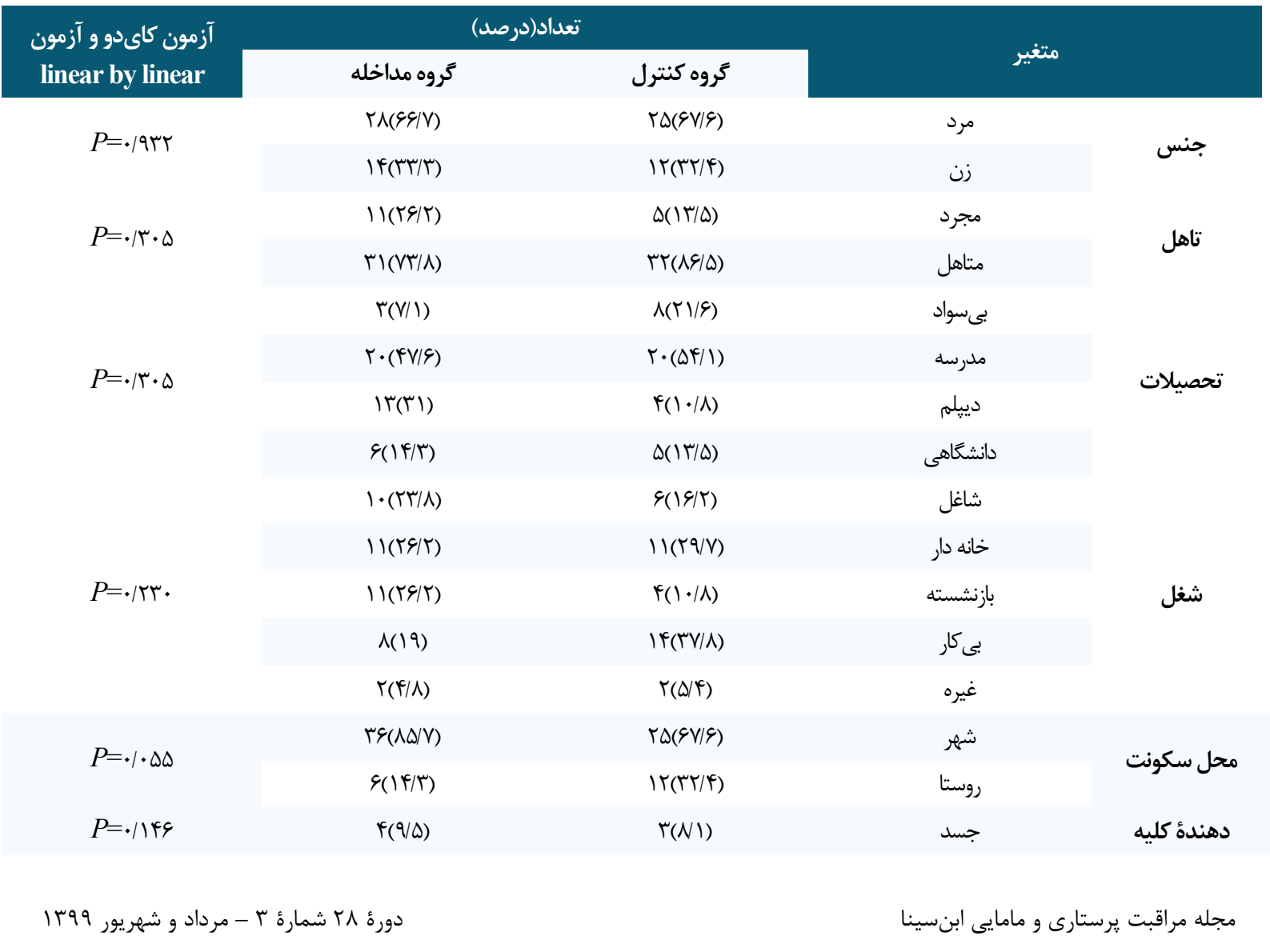




\begin{tabular}{|c|c|c|c|c|}
\hline آزمون كاىدو و آزمون & \multicolumn{2}{|c|}{ تعداد(درصد) ت } & \multirow{2}{*}{ متغير } & \\
\hline linear by linear & كروه مداخله & كروه كنترل & & \\
\hline & $r(q / \Delta)$ & $\cdot(\cdot)$ & خويشاوند زنده & \\
\hline & $r F(\wedge))$ & $M F(9) / 9)$ & غير خويشاوند & \\
\hline \multirow{7}{*}{$P=\cdot /$ T\& } & $\|(Y G / Y)$ & $\mathbb{I r}(r T / Y)$ & يزشك & \multirow{7}{*}{ منبع دريافت } \\
\hline & $\mid r(r \mid)$ & $19(F r / T)$ & 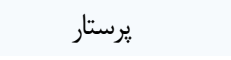 & \\
\hline & $I(Y / Y)$ & $r(N I)$ & اينترنت & \\
\hline & $r(V / 1)$ & $\cdot(\cdot)$ & كتاب & \\
\hline & $\Delta(1) / 9)$ & $r\left(\Delta / Y^{\mathcal{C}}\right)$ & بيماران ديخر & \\
\hline & $I(T / Y)$ & $\cdot(\cdot)$ & 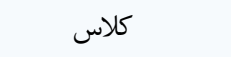 & \\
\hline & $\Lambda(19)$ & $f(1 \cdot / \Lambda)$ & عدم دريافت آموزش & \\
\hline \multirow{3}{*}{$P=\cdot /$ 凡ץ } & $r \Delta(\Delta 9 / \Delta)$ & $r Y(\Delta \vee / \Delta)$ & دخل كمتر از خرج & \multirow{3}{*}{ در آمد } \\
\hline & $I Y(T N G)$ & $q(Y Y / Y)$ & دخل برابر با خرج & \\
\hline & $\Delta(1) / 9)$ & $9(\mid 9 / T)$ & دخل بيشتر از خرج & \\
\hline \multirow{4}{*}{$P=.1 .94$} & $r \Delta(\Delta \vee / \Delta)$ & $1 \Psi(\Pi \Delta / 1)$ & يرفارى خون & \multirow{4}{*}{ علت نارسايى } \\
\hline & $\varphi(\mid f / r)$ & $\Delta(\mid \Gamma / \Delta)$ & بيمارىهاى عفونى & \\
\hline & $r(V / 1)$ & $I(T / V)$ & بيمارىهاى انسدادى & \\
\hline & $g(\mid Y / \mu)$ & $\mid F(\Psi V / \Lambda)$ & ساير بيمارىها & \\
\hline
\end{tabular}

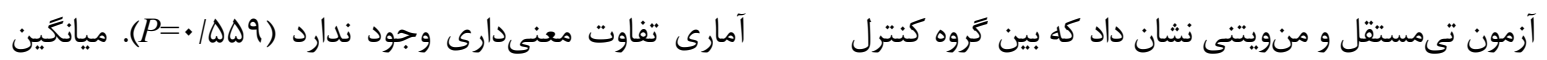

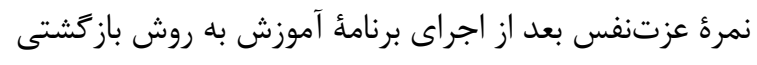

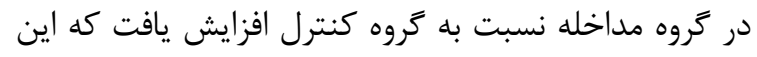

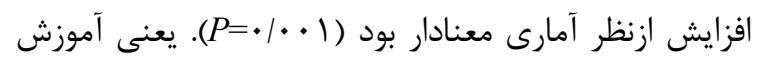

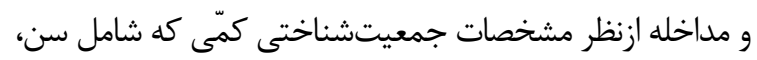

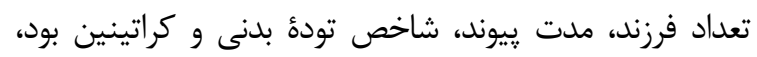

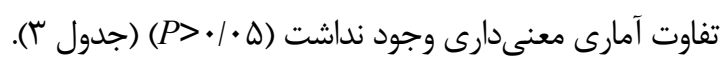

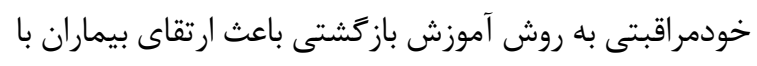

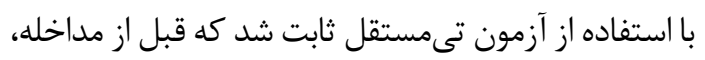

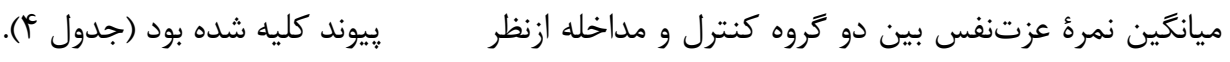
جدول r. مقايسه مشخصات جمعيتشناختى كمى بين دو تروه كنترل و مداخله

\begin{tabular}{|c|c|c|c|c|c|}
\hline \multirow[b]{2}{*}{ آزمون تىمستقل و من } & \multicolumn{2}{|c|}{ كروه مداخله } & \multicolumn{2}{|c|}{ كروه كنترل } & \multirow[b]{2}{*}{ 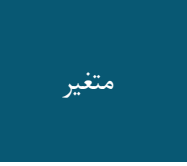 } \\
\hline & ميانگين & ميانكين土|نحراف & ميانگين & ميانكين土|نحراف & \\
\hline מתז & - & $\Gamma \Lambda \pm I T / \Psi \Lambda$ & - & $F I / T V \pm 11 / V$. & سن \\
\hline$P=. / /$ r & גו & $1 / \Delta \cdot \pm 1 / 4$ & 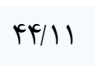 & $\Gamma / \backslash \Lambda \pm 1 / 9 \Delta$ & تعداد فرزند \\
\hline$P=. / / r V$ & $F r / \Delta q$ & $V / 1 \varepsilon \pm \Psi / \Delta r$ & r山/qG & $\Delta / 91 \pm r / 91$ & مدت ييوند \\
\hline$P=\cdot / r \mu$. & - & $r \Delta / F \mid \pm F / \cdot 1$ & - & $r \varepsilon / Y q \pm T / \wedge r$ & شاخص توده بدنى \\
\hline$P=\cdot / V \Delta T$ & - & צr/• & - & $1 / r \Delta \pm \cdot / r \mid$ & كراتينين \\
\hline
\end{tabular}

جدول F. مقايسه ميانكين نمره عزتنفس، قبل و بعد از آموزش به روش بازَشتى بين دو كروه كنترل و مداخله

\begin{tabular}{|c|c|c|c|}
\hline \multirow{2}{*}{ آزمون تىمستقل } & \multicolumn{2}{|c|}{ ميانكين土|نحرافمعيار } & \multirow{2}{*}{ 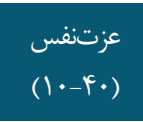 } \\
\hline & مداخله & كنترل & \\
\hline $\mathrm{t}=\cdot / \Delta \wedge \vee \mathrm{df}=\mathrm{V} \vee P=\cdot / \Delta \Delta q$ & 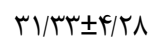 & $r \cdot / V \Lambda \pm r / q \Lambda$ & قبل از مداخله \\
\hline $\mathrm{t}=-r / \uparrow q \Delta \mathrm{df}=\mathrm{V} \vee P=. / \cdots 1$ & $r F / \Delta F \pm F / q$. & $r \cdot / q \uparrow \pm \psi / q q$ & بعد از مداخله \\
\hline
\end{tabular}


• 1 آموزش خودمر اقبتى به روش بازگشتى بر عزتنفس.

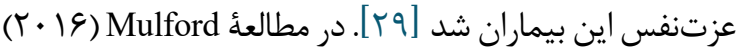

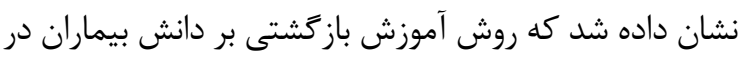
مديريت يرفشارى خون مؤثر است. تفاوت اين مطالعه با باديا

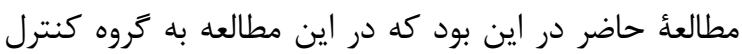

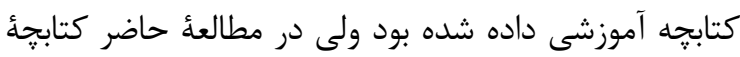

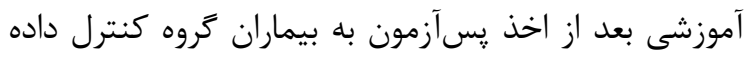

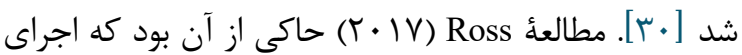

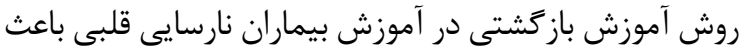

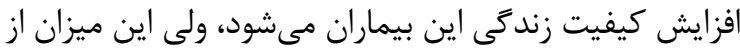

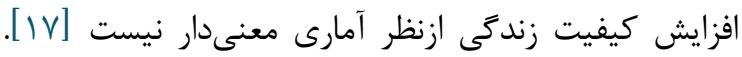

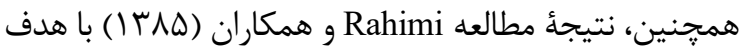

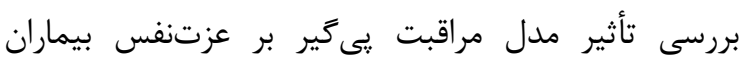

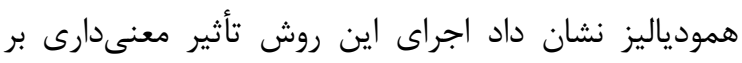

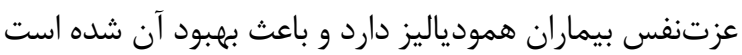

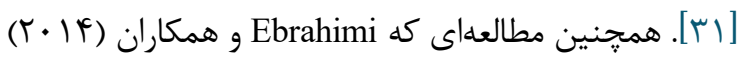

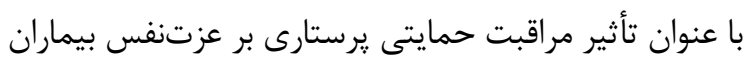

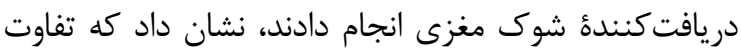

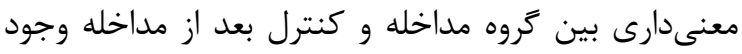

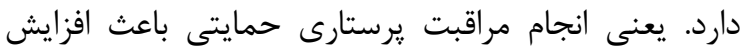

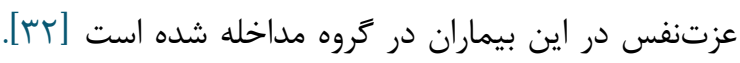
اجراى برنامههاى آموزش در جهت افزايش توانايىهاى بيمار دران مدان در مراقبت از خود و به دنبال آن، كمترشدن وابستكى بيماران

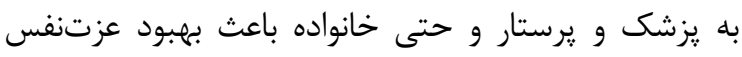

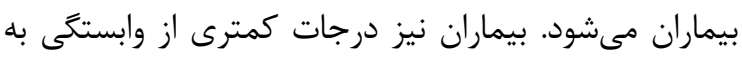

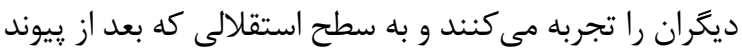

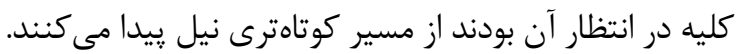
ميسرنبودن فضاى فيزيكى مناسب براى آموزش بيماران، نبودِ

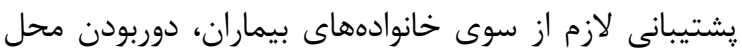

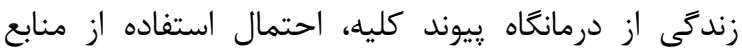

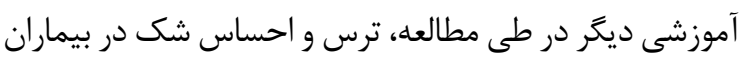

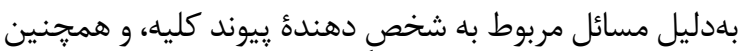
تفاوتهاى فرهنگ از محدوديتهاى اين يزوهش بود.

\section{نتيجهل}

آموزش خودمراقبتى به روش آموزش بازگشتى بر ميزان عزتنفس بيماران با يِيوند كليه تأثير دارد. اين تأثير ازنظر بارك

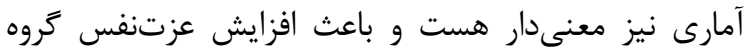

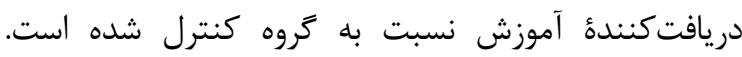

بحث

اين مطالعه با هدف بررسى تأثير آموزش خودمراقبتى به روش بازگشتى بر عزتنفس بيماران با يِيوند كليه انجام شد.

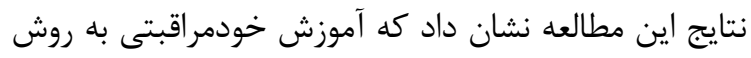

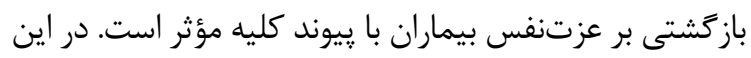

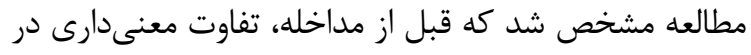

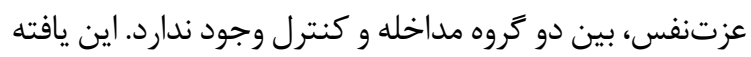

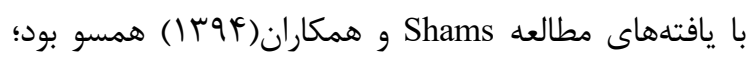
يعنى قبل از مداخله بين عزتنفس بيماران كروه مداخله و

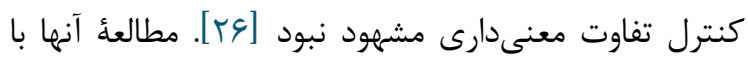

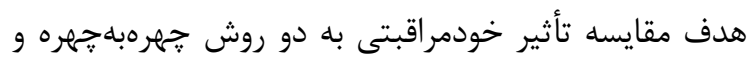

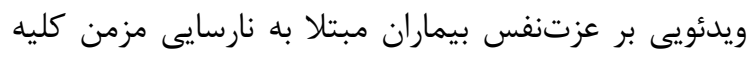
تحت درمان با همودياليز انجام شده بود. Poorgholami و

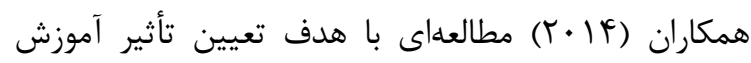

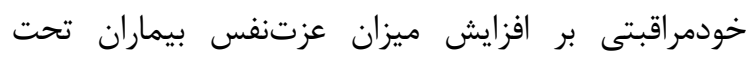

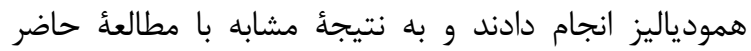
رسيدند و بيماران بعد از مداخله به شكل معنىدارى سطوح

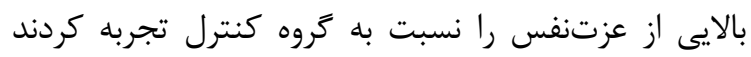

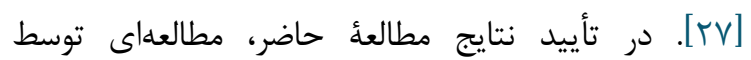
Hemmati

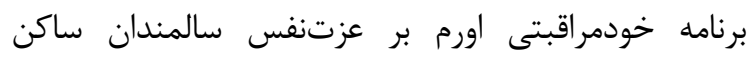
خانههاى سالمندان اروميه انجام شد و ثابت شد كه قبل از ازئ

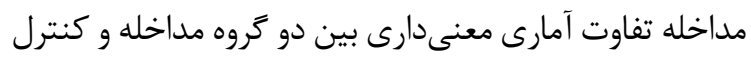

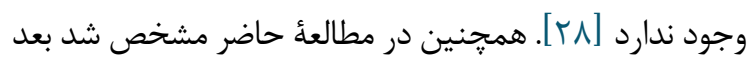

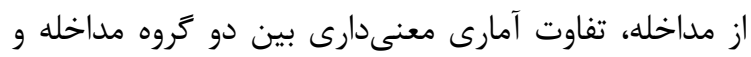

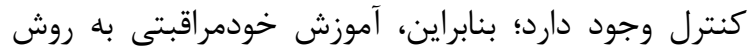

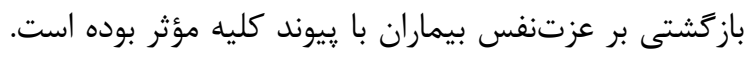

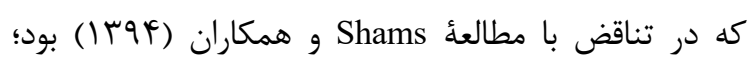
بلهورى كه ميانكين نمرات عزتنفس در كروههاى مداخله افزايش يافته بود، ولى اين افزايش در مقايسه با كروه كنترل

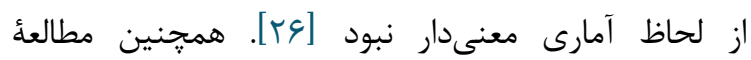
Hemmati

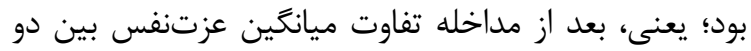

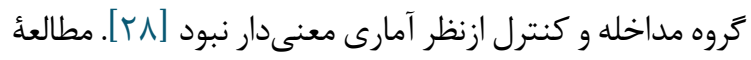

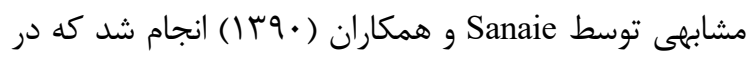

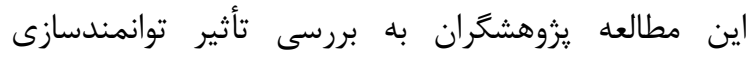

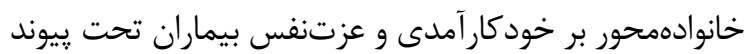
عروق قلب يرداختند كه انجام مداخله موجب افزايش سطح برد 


$$
\text { سياسگزارى }
$$

اين مطالعه از ياياننامة كارشناسىارشد استخراج شده

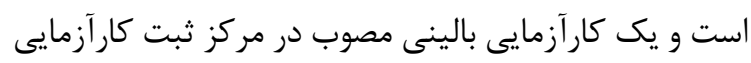

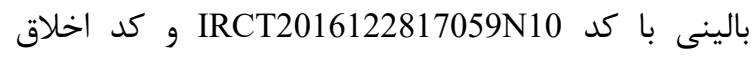
IR.umsu.rec.1395.236

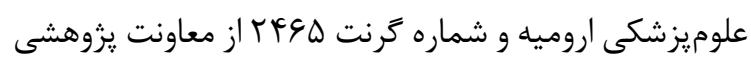

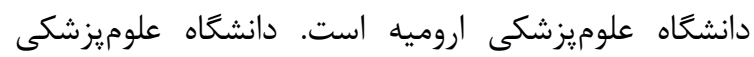

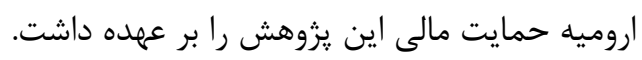

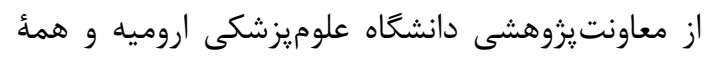

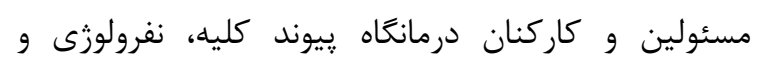

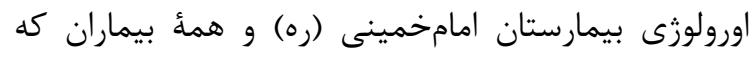
صاحبان اصلى اين بزوهش بودند تشكر مى كنيم.

$$
\text { تعارض در منافع }
$$

بين نويسندكان هيجَّونه تعارضى در منافع وجود ندارد

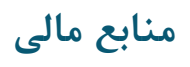

منابع مالى اين مطالعه توسط نويسندًان تامين شده است.

\section{References}

1. Omidi A, Gholinezhad H, Khodawasi M, Roshanaei G. The Correlation of Quality of Life With Social Support for Kidney Transplant Patients. Avicenna J Nurs Midwifery Care. 2018; 26(5):341-8. [DOI:10.30699/sjhnmf.26.a5.341]

2. Salesi M, Shakoor E, Pooranfar S, Koushkie Jahromi M, Roozbeh J. The Effect of a selected exercise on, stress, anxiety and depression in kidney transplant patients. Pars J Jahrom Univ Med Sci. 2014; 12(3):318. [DOI:10.29252/jmj.12.3.38]

3. Tabiban S, Soleimani MA, Bakhshandeh H, Asghary M. Effect of Self-Care Education on the Illness Perception in Patients With Hemodialysis: A Randomized Control Trial. Avicenna J Nurs Midwifery Care. 2019; 27(2):73-81. [DOI:10.30699/sjhnmf.27.2.73]

4. Soltannezhad F, Farsi Z. An investigation of quality of life in kidney transplant patients. J Military Car Sci. 2015; 2(3):167-72

[DOI:10.18869/acadpub.mcs.2.3.167]

5. Chatterjee SN. Manual of renal transplantation. Berlin: Springer Science \& Business Media; 2012.

6. Javandoust Gharehbagh F, Khalkhali H, Taghizadeh Afshari A, Nourooz-Zadeh J. Delayed graft function and its associated risk factors in Imam Khamenei kidney transplantation Unit . J Stud Med Sci. 2018; 29(6):398-410.

$$
\begin{aligned}
& \text { بنابراين، با قبول اثربخشبودن روشهاى آموزشى ديكر كه } \\
& \text { بدون توجه به ميزان يادكيرى و ميزان تسلط بيمار و يا هر فرد }
\end{aligned}
$$

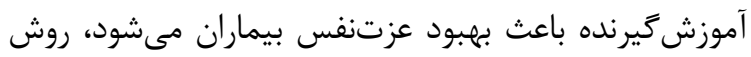

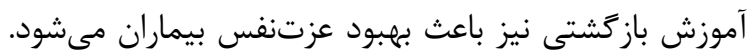

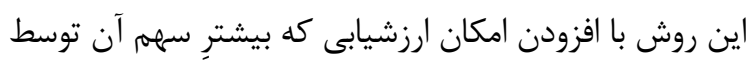

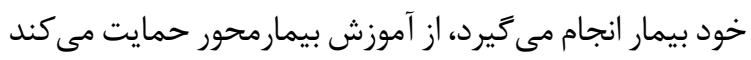

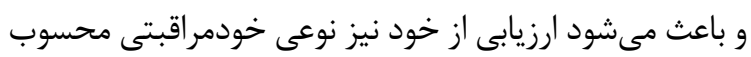

$$
\begin{aligned}
& \text { شود و نسبت به روشهاى سنتى كه بهطور يكسرفه و بدون }
\end{aligned}
$$

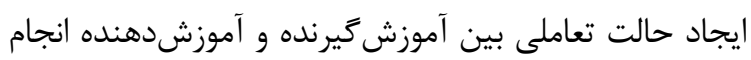

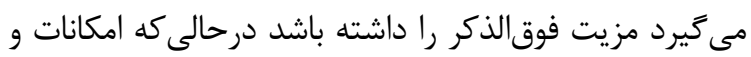

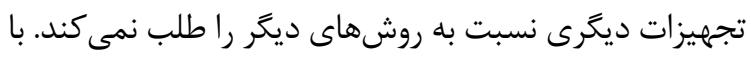

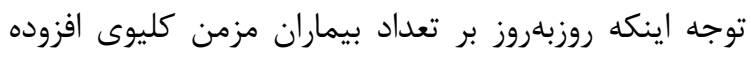

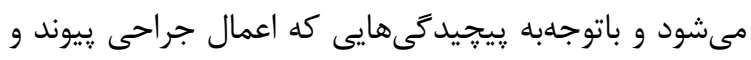

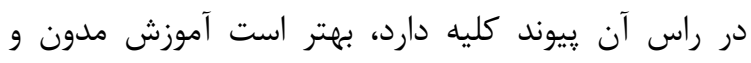

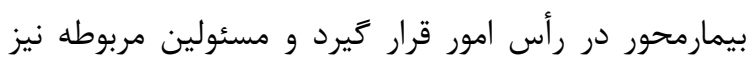

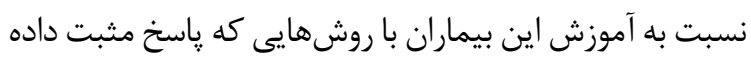

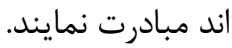

7. Ghadami A, Memarian R, Mohamadi E, Abdoli S. Patients' experiences from their received education about the process of kidney transplant: A qualitative study. Iran J Nurs Midwifery Res. 2012; $17(2$ Suppl1):S157.

8. Gentile S, Beauger D, Speyer E, Jouve E, Dussol B, Jacquelinet C, et al. Factors associated with healthrelated quality of life in renal transplant recipients: results of a national survey in France. Health Qual Life Out J. 2013; 11(1):88. [DOI:10.1186/1477-7525-1188] [PMID] [PMCID]

9. Karimi S, Vanaki Z, Bashiri H, Vanaki SA. The effect of Orem self-care ability of patients with colorectal cancer. Avicenna J Nurs Midwifery Care. 2016; 24(2):105-12.

10. Salomé GM, Almeida SAd, Silveira M. Quality of life and self-esteem of patients with intestinal stoma. J Coloproctol. 2014; [DOI:10.1016/j.jcol.2014.05.009]

34(4):231-9.

11. Marashi SA, Mehrabiyan T. The Relationship of Prayer and Spiritual Health with Self-Esteem of Patients Treated with Hemodialysis in Ilam. J Military $\begin{array}{lll}\text { Care } & \text { Sci. 2016; } & \text { 2(4):214-20. }\end{array}$ [DOI:10.18869/acadpub.mcs.2.4.214]

12. Sadock BJ, Sadock VA. Kaplan and Sadock's synopsis of psychiatry: Behavioral sciences/clinical psychiatry. Philadelphia: Lippincott Williams \& Wilkins; 2011. 
13. Beer J. Body image of patients with ESRD and following renal transplantation. British J Nursing. 1995 [DOI:10.12968/bjon.1995.4.10.591] [PMID]

14. Wilson R, Brown DR, Boothe MAS, Weng FL. Improving the Delivery of Patient Education about Kidney Transplant in a Transplant Center. Prog Transplant. 2012; 22(4):403-12. [DOI:10.7182/pit2012716] [PMID]

15. Munro V, Morello A, Oster C, Redmond C, Vnuk A, Lennon $\mathrm{S}$, et al. E-learning for self-management support: introducing blended learning for graduate students - a cohort study. BMC Med Educ. 2018; 18(1):219. [DOI:10.1186/s12909-018-1328-6] [PMID] [PMCID]

16. Mahmoudi M, Asgari P, Bahramnezhad F, Golitaleb $\mathrm{M}$, Rafiei $\mathrm{M}$. The effect of inquiry-based training on nursing students operational skills in clinical setting. Educ Ethic Nurs. 2015; 4(3):27-33.

17. Ross DJ. The Effects of the Teach Back Method on Heart Failure Patients. Arizona: Grand Canyon University; 2016.

18. Hatefi Moadab N, Elahi N, Moradbeygi K, Fakhri M, Latifi S, Elhami S. Effect of Teach- Back Educational Method on Surgical Anxiety in Primiparous Cesarean Section Women. J Clin Res Paramed Sci. 2015; 4(2):169-77.

19. Dalir M, Mashouf S, Esmailpourzanjani S. The Effect of Spiritual Self-Care Education on the Care Burden of Mothers With Children Hospitalized in Intensive Care Units for Open Heart Surgery. cmja. 2020; 10 (1) :3445

20. Salavati M, Khatiban M, Moghadari Koosha B, Soltanian A. Evaluating the effect of teach back education on self-care behaviours and quality of life in patients with myocardial infarction in 2015: A randomised controlled trial. Avicenna J Nurs Midwifery Care. 2017; 25(1): 1-8. [DOI:10.21859/nmj-25011]

21. Tamura-Lis W. Teach-back for quality education and patient safety. Urol Nurs. 2013; 33(6):267-71. [DOI:10.7257/1053-816X.2013.33.6.267] [PMID]

22. Kornburger C, Gibson C, Sadowski S, Maletta K, Klingbeil C. Using "teach-back" to promote a safe transition from hospital to home: an evidence-based approach to improving the discharge process. J Pediatr Nurs. 2013;28(3):282-91 [DOI:10.1016/j.pedn.2012.10.007] [PMID]

$$
\text { كا1 آموزش خودمراقبتى به روش بازگشتى بر عزتنفس }
$$

23. Oshvandi K, Jokar M, Khatiban M, Keyani J, Yousefzadeh MR, Sultanian AR. The effect of self care education based on teach back method on promotion of self care behaviors in type II diabetic patients: a clinical trial study. Iran J Diabetes Lipid Disord. 2014; 13(2):131-43.

24. Seyedfatemi N, Heydari M, Hoseini A. Self Esteem and its Associated Factors in Patients with Multiple Sclerosis. Iran J Nurs. 2012; 25(78):14-22.

25. Mohammadi N. Sajadi Negad M. Psychometric evaluation of measures concerns about body image questionnaire and test the communication model, BMI, dissatisfaction with body image and self esteem in adolescent girls. J Psychol Stud. 2006; 1(3):85-101.

26. Shams s, Hemmati m, Sheikhi n. comparison of the effects of face-to-face and video instructional methods on self-esteem of the patients with hemodialysis. J Urmia Nurs Midwifery Fac. 2015; 13(6):544-52.

27. Poorgholami F, Javadpour S, Saadatmand V, Jahromi MK. Effectiveness of self-care education on the enhancement of the self-esteem of patients undergoing hemodialysis. Glob J Health Sci. 2015; 8(2):132-6. [DOI:10.5539/gihs.v8n2p132] [PMID] [PMCID]

28. Hemmati M, Hashemlo L, Khalkhali H. The effect of implementing orem's self-care model on the selfesteem of elderlies resident of nursing home in Urmia. Medic-Surg Nurs J. 2012; 1(1):18-23.

29. Sanaie N, Nejati S, Zolfaghari M, Alhani F, Kazem Nejad A. The effect of family-centered empowerment in self efficacy and self esteem in patients undergoing coronary bypass graft surgery. J Res Dev Nurs Midwifery. 2013; 10(2):44-53.

30. Mulford DL. Using the teach-back method to improve self-care behaviors. Virginia: Hampton University; 2016.

31. Rahimi A, Ahmadi F, Gholyaf M. effect of applying continuous care model on self-esteem in hemodialysis patients. Razi J Med Sci. 2006; 13(52): 123-34.

32. Ebrahimi H, Navidian A, Keykha R. Effect of supportive nursing care on self esteem of patients receiving electroconvulsive therapy: A randomized controlled clinical trial. J Caring Sci. 2014; 3(2):14956 . 